\title{
ERRATUM
}

Erratum doi: https://doi.org/10.1007/s00376-020-2013-3

\section{Erratum to: Could the Recent Taal Volcano Eruption Trigger an EI Niño and Lead to Eurasian Warming?}

\author{
Fei LIU ${ }^{1,2,3}$, Chen $\mathrm{XING}^{3}$, Jinbao $\mathrm{LI}^{4}$, Bin $\mathrm{WANG}^{5}$, Jing $\mathrm{CHAI}^{3}$, Chaochao GAO ${ }^{6}$, \\ Gang $\mathrm{HUANG}^{7}$, Jian $\mathrm{LIU}^{8}$, and Deliang CHEN ${ }^{9}$ \\ ${ }^{1}$ School of Atmospheric Sciences and Guangdong Province Key Laboratory for Climate Change and \\ Natural Disaster Studies, Sun Yat-sen University, Zhuhai 519082, China \\ ${ }^{2}$ Southern Marine Science and Engineering Guangdong Laboratory (Zhuhai), Zhuhai 519082, China \\ ${ }^{3}$ Earth System Modeling and Climate Dynamics Research Center, Nanjing University of Information Science and \\ Technology, Nanjing 210044, China \\ ${ }^{4}$ Department of Geography, University of Hong Kong, Pokfulam, Hong Kong \\ ${ }^{5}$ Department of Atmospheric Sciences and International Pacific Research Center, \\ University of Hawaii at Manoa, Honolulu, HI 96822, USA \\ ${ }^{6}$ Department of Environmental Science, Zhejiang University, Hangzhou 310058, China \\ ${ }^{7}$ State key Laboratory of Numerical Modeling for Atmospheric Sciences and Geophysical Fluid Dynamics, \\ Institute of Atmospheric Physics, Chinese Academy of Sciences, Beijing 100029, China \\ ${ }^{8}$ Key Laboratory for Virtual Geographic Environment, Ministry of Education; Jiangsu Provincial State Key Laboratory \\ Cultivation Base of Geographical Environment Evolution; School of Geography Science, \\ Nanjing Normal University, Nanjing 210023, China \\ ${ }^{9}$ Department of Earth Sciences, University of Gothenburg, Gothenburg 405 30, Sweden
}

ESM to : Liu, F, and Coauthors, 2020: Could the recent Taal Volcano eruption trigger an El Niño and lead to Eurasian warming? Adv. Atmos. Sci., 37(7), 663-670, https://doi.org/org/10.1007/s00376-020-2041-z.

In the third column of the five row of Table 1, " $120.4^{\circ} \mathrm{W}$ " should be "120.4 ${ }^{\circ} \mathrm{E}$.

The online version of this original article can be found at https://doi.org/10.1007/s00376-020-2041-z 